\title{
Microporous structures in natural polymer
}

\author{
Maciej Borowczak ${ }^{1, *}$, and Stanisław Frąckowiak ${ }^{1}$ \\ ${ }^{1}$ Wroclaw University of Science and Technology, Faculty of Environmental Engineering, \\ Wybrzeze Wyspianskiego 27, 50-370 Wroclaw, Poland
}

\begin{abstract}
Electrospinning of biodegradable poly (butylene succinate) has been performed from different solvent systems. Alternation of process parameters resulted in respective changes of the surface structure topography which was evaluated by using scanning electron microscopy (SEM).
\end{abstract}

\section{Introduction}

In recent years, biodegradable materials have gained increasing popularity and application area due to lack of environmental impact compared to their synthetic counterparts obtained from crude oil. Among those materials is polybutylene succinate (PBS) which can be obtained from the petrochemical industry or fully naturally by synthesis of succinic acid and 1,4-butanediol derived from wheat. In addition, PBS has mechanical and thermal properties similar to synthetic materials such as polypropylene (PP) and polyethylene (PE), which can be processed by foaming, injection molding, extrusion, etc. [1]. Due to above properties and high barrier to oxygen, PBS is increasingly used on the packaging market as a replacement for traditional polymer materials, having an additional advantage: the possibility of fast biodegradation. There are also other methods of utilizing biodegradable materials, but they require use of other processing methods than those currently used. One of these methods is electrospinning. Key of the process is production of nanofibres with diameters reaching up to $1 \mu \mathrm{m}$ from molten polymers (melt spinning) or their solutions in an electric field [2]. This technology allows to obtain structures with a wide application potential, used as dressing materials, drug carriers, tissue scaffolds or filter mats [3].

The purpose of the work was to determine the process parameters required to obtain porous structures in the PBS electrospinning process in a two solvents system:

- I series - chloroform

- II series - Mixture of chloroform and methylene chloride in a 4:1 volume ratio

\footnotetext{
*Corresponding author: Maciej.Borowczak@wp.pl
} 


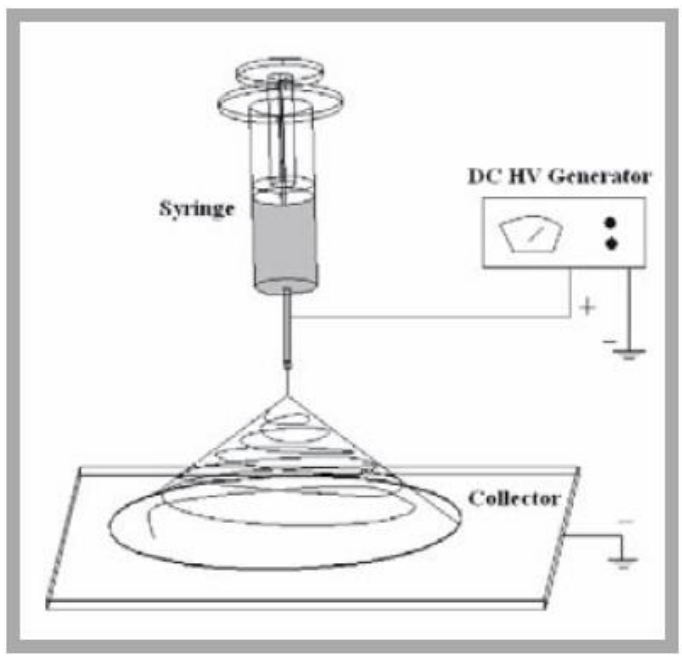

Fig. 1. Diagram of the electrospinning process [3].

\section{Materials and methods}

\subsection{Characterization of reagents}

The tests were carried out on a series of solutions of different concentrations (see Table 2). Solutions in series I were made using one solvent (chloroform) from "CHEMPUR" with $99.5 \%$ purity and PBS granulate from NaturePlast, under the manufacturer's name: NATUREPLAST PBE 003 BB. The characteristics of the material is shown in the Table 1. Series II are solutions made with a mixture of two solvents, chloroform and methylene chloride (DCM) ("STANLAB" company) and PBS granules mentioned above.

Table 1. NATUREPLAST PBE 003 BB physical parameters.

\begin{tabular}{|c|c|}
\hline Parameter & Value \\
\hline Melting temperature, ${ }^{\circ} \mathrm{C}$ & $110-120$ \\
\hline Tensile elongation at break, $\%$ & 330 \\
\hline MFR $\left(2.16 \mathrm{~kg}, 190^{\circ} \mathrm{C}\right), \mathrm{g} / 10 \mathrm{~min}$ & $2-5$ \\
\hline
\end{tabular}

\subsection{Procedure for the solutions preparation}

For each of the tested solutions, the preparation procedure was as follows:

1. PBS granulate was weighed. PBS granulate was weighed on the analytical balance

2. Addition of measured solvent volume - I series: $40 \mathrm{~cm}^{3}$ of CHF, II series: $40 \mathrm{~cm}^{3}$ of CHF: $10 \mathrm{~cm}^{3}$ of DCM $\left(50 \mathrm{~cm}^{3}\right.$ in total)

3. Prepared solution was placed on a magnetic stirrer to accelerate the dissolution rate of the granulate at room temperature.

4. The prepared clear solution was poured to the syringe and placed in the electrospinning set pump. 
Table 2. Concentration of the PBS solutions used for electrospining process.

\begin{tabular}{|c|c|c|}
\hline $\begin{array}{c}\text { Sample } \\
\text { number }\end{array}$ & Series no. & Concentration \\
\hline 1 & Series I & $7 \%$ \\
\hline 2 & Series I & $15 \%$ \\
\hline 3 & Series II & $8 \%$ \\
\hline
\end{tabular}

\subsection{Research system}

Electrospinning of polymer solutions was carried out with a Bioinicia FLUIDNATEK LE 10 device (Fig. 2). The device consists of a polymer solution tank (syringe) with a nozzle, two electrodes, a DC power supply and a collector in the form of a grounded plate on which the spun fibre is deposited. The polymer solution exiting through the nozzle is subjected to electrostatic field forces that give it the shape of a fibre. The fibre moves towards the collector in a spiral motion along the force lines of the electrostatic field, at the same time reducing its diameter [4].

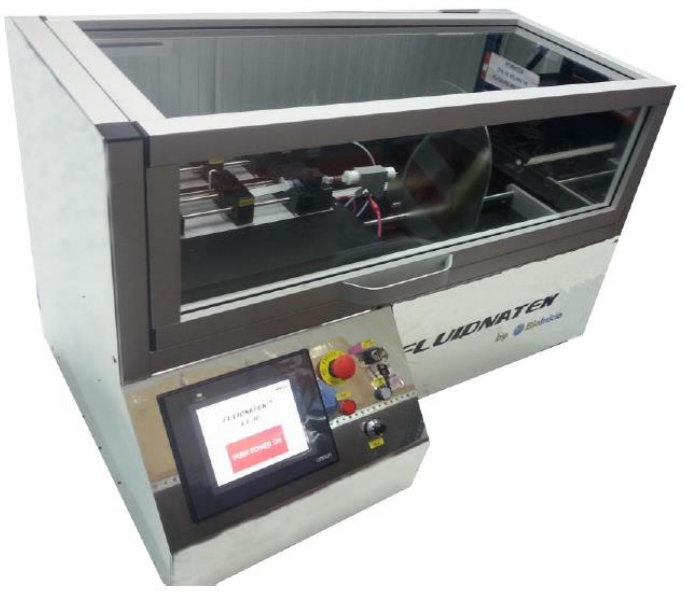

Fig. 2. FLUIDNATEK LE-10.

\subsection{Parameters regulation}

There were seven parameters (among all) identified as crucial for the process and put under investigation. All of them may be divided into three groups:

\section{A. Ambient parameters:}

- Humidity - affects the electrical conductivity of the solution, along with an increase in humidity to about $30-50 \%$, the fibres become thinner. This is a desirable phenomenon, because it is possible to use a lower voltage, with solutions even with increased viscosities [4].

- Temperature - affects the rate of evaporation of the solution, by reducing its viscosity. At higher temperatures fibres with more homogeneous diameters are obtained [5].

B. Electrospinning equipment parameters :

- Distance of the collector from the nozzle - The distance between the needle and the collector should be large enough to prevent an electric spark, but it should not be too large due to the possibility of premature solvent evaporation [5]. 
- The speed of the polymer solution feed - the rate of polymer solution feeding affects the formation of the Taylor cone. Too high speed of the syringe piston may cause the solution to drip from the dispensing nozzle without the formation of a suitably thin thread, too low speed, however, may lead to the thread break or clogging the solution dispensing nozzle [6].

- Electric field intensity - in most cases the use of higher voltage leads to better stretching of the solution stream, results in higher Coulomb interactions and the generation of smaller fibre diameters. Too high tension increases the tendency to form beads. Lower voltage, lower acceleration and weaker electric field favours the formation of thinner nanofibres [5].

- Needle diameter - the smaller nozzle diameter, the greater possibility of jamming. It has also been found that reducing the inner diameter of the aperture can result in a reduction in fibre diameter. This phenomenon is caused by the increase in the surface tension of the drops [2].

\section{Solution parameters:}

- Concentration - is one of the main parameters defining the morphology of the obtained fibres. Too low concentration of polymer in the solution causes the formation of beads or droplets, at the optimal concentration, a homogeneous fibre of constant diameter is created over its entire section. The last option is higher than optimal concentration. In this case, the end product of the process is the ribbon [2].

\subsection{FT-IR (ATR) measurement}

The infrared spectra was obtained for material before dissolution and after electrospinning process. Investigation was performed in the wavenumber range $600-4000 \mathrm{~cm}^{-1}$ using Bruker Tensor 37 apparatus and Opus software. The samples of electrospun materials were placed in the apparatus without any further processing. PLA pellets (solid material before solving) were grinded. Prior to that, regarding the pellets' toughness, the materials were immersed in a liquid nitrogen for about 3 minutes. The powdered polymer sample was then placed into the apparatus measuring cell and the spectra was recorded. Baseline correction, normalization, spectrum smoothening and any further necessary calculations (like peak picking) were done within the measuring procedure time-length. No spectra processing was done after the measurement.

\subsection{SEM investigation}

Scanning electron microscope was used to investigate the morphology of the process products. It was carried out using VEGA Tescan 3 , gun voltage $5.0 \mathrm{kV}$, magnification rate is mentioned on the respective pictures and text. Samples were gold sputtered (Kressington 108 sputter coater) for $60 \mathrm{~s}$ and $40 \mathrm{~mA}$ current.

\section{Results and discussion}

\subsection{Morphology}

PBS solutions made using chloroform were used. Pictures on Fig. 3 (a,b,c) and 4 (d,e,f) show results corresponding to I series solutions. Pictures on Fig. 5 (a,b) refer to solvents mixture. 
As it can be seen from Fig. 3 (a,b,c) and 4 d, PBS tends to form elliptical structures under the following conditions (voltage: $6.5 \mathrm{kV}$; flow rate: $0.9 \mathrm{~cm}^{3} / \mathrm{h}$; distance $15 \mathrm{~cm}$ ). Diameters of individual structures oscillated around $20-30 \mu \mathrm{m}$, and pore diameters from 5 to $10 \mu \mathrm{m}$. The obtained structure was characterized by high density and a constant size not exceeding $30 \mu \mathrm{m}$ in average (Fig. 3 (a,b,c) and 4 d). Increasing PBS concentration to $15 \%$ resulted in only slight changes of sample morphology. Mostly observed were beads with single or multiple pores. Their diameter was larger (ranging from 25 to $50 \mu \mathrm{m}$ (Fig. 3c and Fig. 4e)).
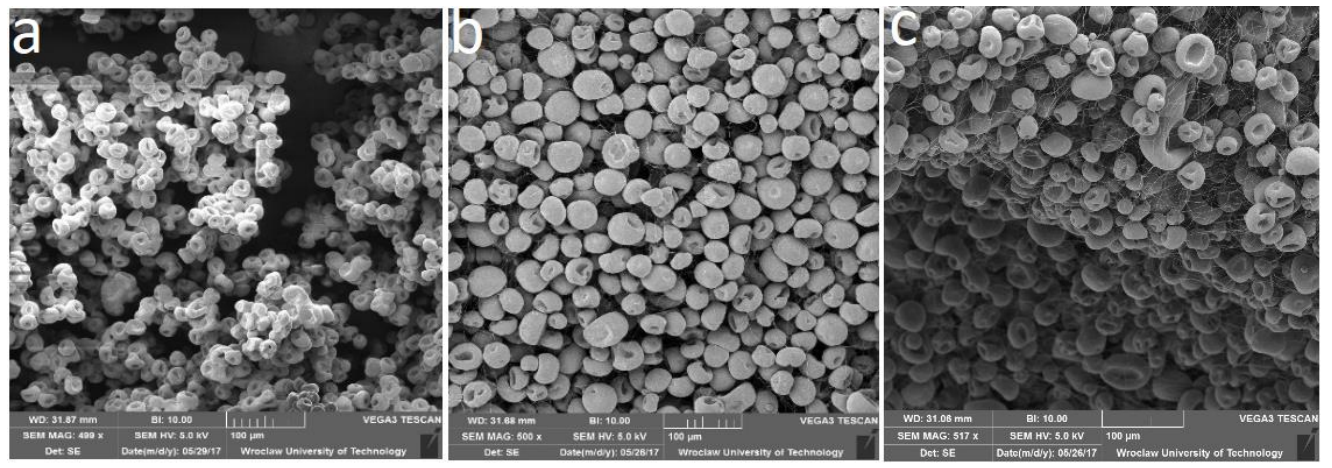

Fig. 3. SEM photo: a) PBS 7\%, Voltage: $6.5 \mathrm{kV}$, Flow rate: $0.90 \mathrm{~cm}^{3} / \mathrm{h}$, Solvent: chloroform, Distance: $15 \mathrm{~cm}$, Magnification: 500x; b) PBS 15\%, Voltage: $6.5 \mathrm{kV}$, Flow rate: $0.65 \mathrm{~cm}^{3} / \mathrm{h}$, Solvent: chloroform, Distance: $15 \mathrm{~cm}$, Magnification: 500x; c) PBS 15\%, Voltage: $7.5 \mathrm{kV}$, Flow rate: 0.75 $\mathrm{cm}^{3} / \mathrm{h}$, Solvent: chloroform, Distance: $15 \mathrm{~cm}$, Magnification: 500x.

Increasing the voltage to $7.5 \mathrm{kV}$ and polymer flow to $0.75 \mathrm{~cm}^{3} / \mathrm{h}$ resulted in an increase of number and size of pores but simultaneously pores mean size and its distribution increased. Size of separate beads ranged from 20 to $70 \mu \mathrm{m}$. This differentiation was most likely caused by the increase of solution flow rate which eventually led to uneven distribution of the polymer from the needle in the electric field and the formation of agglomerates of different sizes (Fig. 3c and Fig. 4f). In addition, in both samples a network of fibres surrounding the main structure was observed (see Fig. 4 (e,f)). The reason for the formation of this network is probably the concentration of polymer in the solution, reaching the level high enough for fibre formation. This thesis may be supported by the observation made for $7 \%$ solution, where lack of fibres were observed.
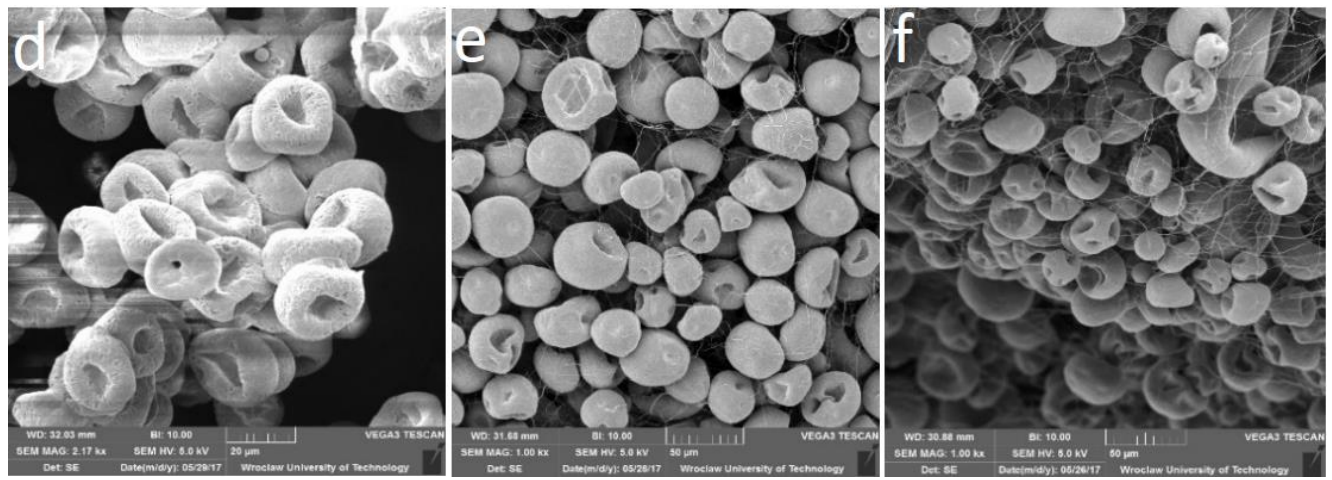

Fig. 4. SEM photo: d) PBS 7\%, Voltage: $6.5 \mathrm{kV}$, Flow rate: $0.90 \mathrm{~cm}^{3} / \mathrm{h}$, Solvent: chloroform, Distance: $15 \mathrm{~cm}$, Magnification: 500x; e) PBS 15\%, Voltage: $6.5 \mathrm{kV}$, Flow rate: $0.65 \mathrm{~cm}^{3} / \mathrm{h}$, Solvent: chloroform, Distance: $15 \mathrm{~cm}$, Magnification: 500x; f) PBS 15\%, Voltage: $7.5 \mathrm{kV}$, Flow rate: 0.75 $\mathrm{cm}^{3} / \mathrm{h}$, Solvent: chloroform, Distance: $15 \mathrm{~cm}$, Magnification: 500x. 
An attempt to increase pore density on the product surface was made. Thus a solution was prepared basing on two solvents with different boiling points in a volume ratio of $4: 1$ (CHF:DCM). Analysis of the SEM pictures lead to the conclusion that the chosen solvent system does not allow sufficiently high evaporation rate between the tip of the needle and the collector, which results in single beads and spheres on the background of the dried PBS patches. This fact is depicted on the Fig. $5(\mathrm{a}, \mathrm{b})$
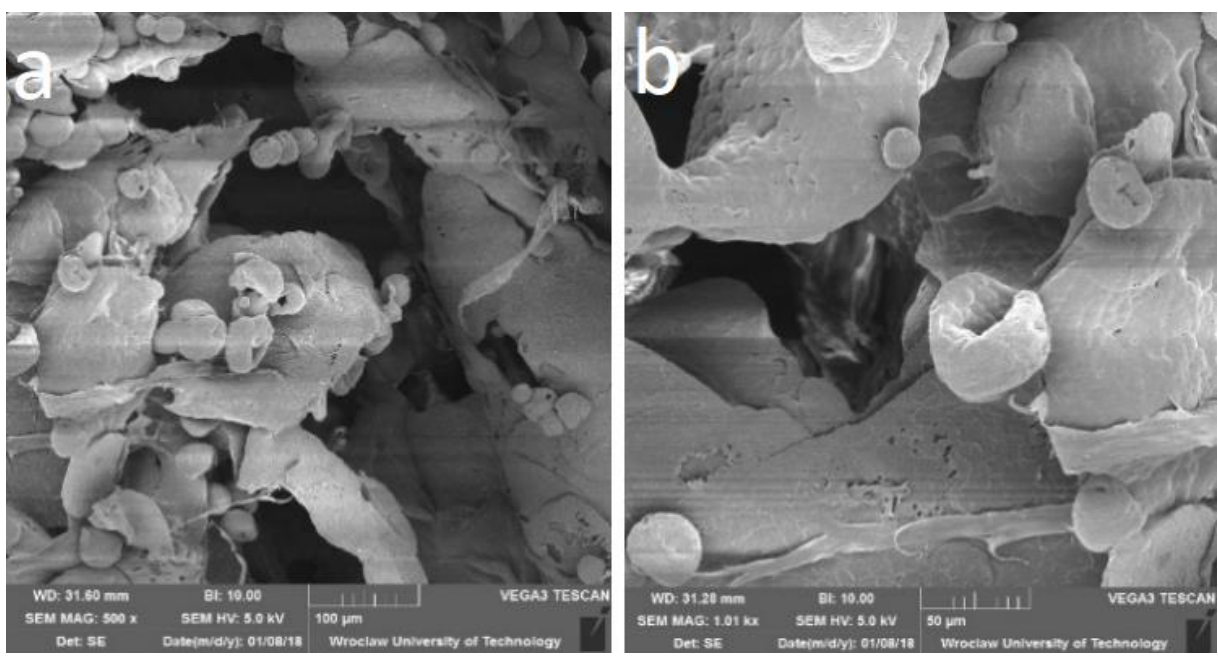

Fig. 5. SEM photo: a) PBS $8 \%$, Voltage: $5.5 \mathrm{kV}$, Flow rate: $1.5 \mathrm{~cm}^{3} / \mathrm{h}$, Distance: $21 \mathrm{~cm}$, Solvents: chloroform + DCM, Magnification: 500x; b) PBS $8 \%$, Voltage: $5.5 \mathrm{kV}$, Flow rate: $1.5 \mathrm{~cm}^{3} / \mathrm{h}$, Distance: $21 \mathrm{~cm}$, Solvents: chloroform + DCM, Magnification: 1000x.

FT-IR (ATR) investigation was provided to reveal whether the overall process (dissolution and electrospinning) has any significant influence on the structure of biopolymer. As it can be observed on the figure below, no meaningful modification of spectra occurred thus steric structure of biopolymer remained unchanged.

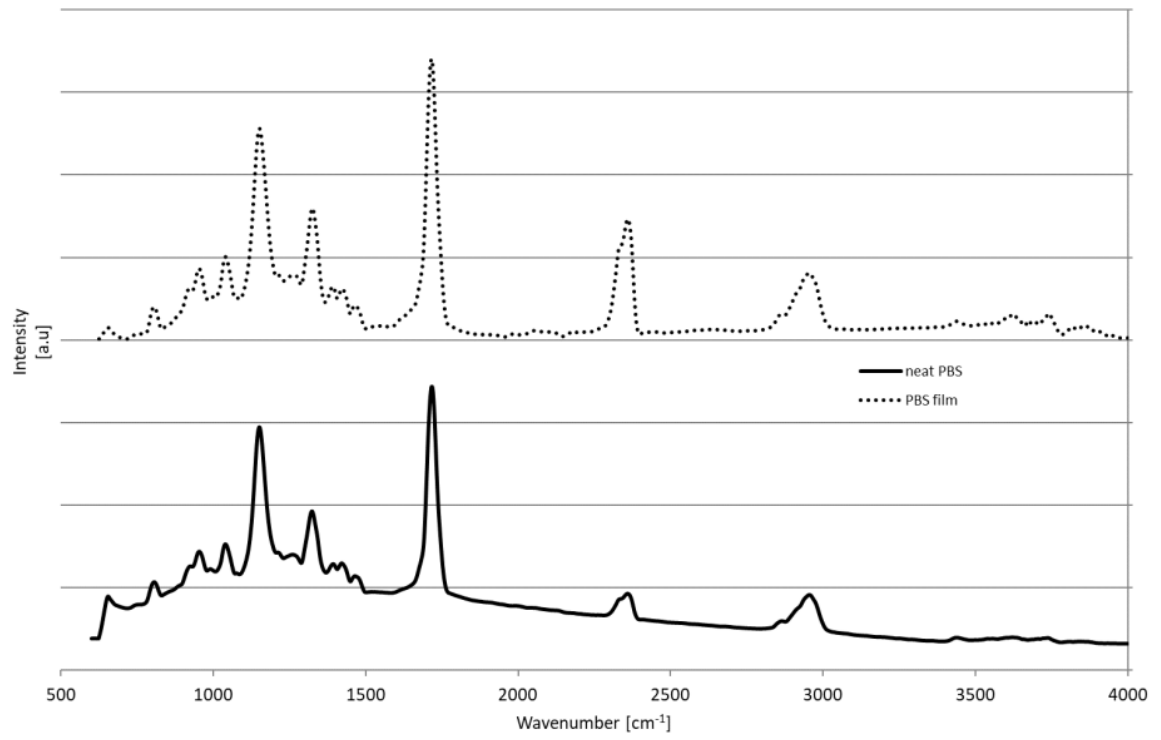

Fig. 6. FT-IR spectra of neat PBS (solid line) and electrospun PBS film (dotted line). 


\section{Conclusions}

- The possibility of producing porous structures in a controlled manner using the electrospinning method from the solution has been demonstrated;

- Porous structures were obtained from solutions with polymer concentrations of $7 \%$ and $15 \%$, having single agglomerates sizes ranging from 20 to $30 \mu \mathrm{m}$ and 20-70 $\mu \mathrm{m}$ (respectively);

- Along with the increase of PBS content in the solution, the shape irregularity of individual structures and the number of pores appearing on their surface increased. In addition, a network of fibres stabilizing the porous structure was observed, which occurred in the $15 \%$ solution. The higher the working voltage was applied, the denser the network became;

- In the II series it was not possible to obtain porous structures. This fact was most probably caused by too high boiling point of the second solvent, which was methylene chloride, so that the material still got wet on the collector;

- The main factor determining the size of the observed pores was the flow rate of the polymer solution;

- Established processing way did not influence the chemical structure (thus properties) of the PBS polymer.

\section{References}

1. N. Stoyanova, D. Paneva, R. Mincheva, A. Toncheva, N. Manolova, P. Dubois, I. Rashkov Mater. Sci. Eng. 41, 119 (2014)

2. S. Ramakrishna, K. Fujihara, W. Teo, T. Lim, Z. Ma, An introduction to Electrospinning and Nanofibers (World Scientific Publishing Company, Singapore, 2005)

3. Y. Liu, J.-H. He, J.-Y. Yu, Fibres Text. East. Eur. 15, 30 (2007)

4. D. Kołbuk, Dissertation: Wpływ warunków elektroprzędzenia na strukture $i$ wtaściwości jedno $i$ dwusktadnikowych nanowtókien polimerowych stosowanych $w$ inżynierii tkankowej (Institute of Physics of the Polish Academy of Sciences, Warsaw, 2012)

5. K. Kurzydłowski, M. Lewandowska, Nanomateriały inżynierskie konstrukcyjne i funkcjonalne (PWN, Warszawa, 2008)

6. A. Baranowska-Korczyc, Dissertation: Pótprzewodnikowe sensory oparte na nanowłóknach otrzymywanych metoda elektroprzedzenia (Institute of Physics of the Polish Academy of Sciences, Warsaw, 2010) 